Meta

Journal des traducteurs

Translators' Journal

\title{
Translation and Identity
}

\section{Neusa Da Silva Matte}

Volume 41, numéro 2, juin 1996

Traduction et terminologie au Brésil

Translation and Terminology in Brazil

URI : https://id.erudit.org/iderudit/003601ar

DOI : https://doi.org/10.7202/003601ar

Aller au sommaire du numéro

Éditeur(s)

Les Presses de l'Université de Montréal

ISSN

0026-0452 (imprimé)

1492-1421 (numérique)

Découvrir la revue

\section{Citer cet article}

Da Silva Matte, N. (1996). Translation and Identity. Meta, 41(2), 228-236.

https://doi.org/10.7202/003601ar

\section{Résumé de l'article}

L'auteur nous présente une partie de ses recherches sur la traduction et la poésie. Il examine ici la traduction à partir de deux présuppositions : 1) la traduction est un processus qui extrapole la dimension textuelle ; et 2) ce processus peut être débattu dans un contexte d'identité textuelle. d'utilisation que vous pouvez consulter en ligne.

https://apropos.erudit.org/fr/usagers/politique-dutilisation/ 


\title{
TRANSLATION AND IDENTITY
}

\author{
Neusa Da Silva MatTe \\ Universidade Federal do Rio Grande do Sul, Porto Alegre, Brazil
}

\begin{abstract}
Résumé
L'auteur nous présente une partie de ses recherches sur la traduction et la poésie. Il examine ici la traduction à partir de deux présuppositions : I) la traduction est un processus qui extrapole la dimension textuelle; et 2) ce processus peut être débattu dans un contexte d'identité textuelle.
\end{abstract}

Abstract

The author presents part of her research on translation theory and poetry. Her approach is based on two assumptions: 1) that translation is a process which extrapolates textual dimension; 2) that this process can be tackled from the perspective of (textual) identity.

Based on the concepts of identity, difference, mediation as used by Heidegger (Identidad y Diferencia) ${ }^{1}$, Derrida (L'écriture et la différence ${ }^{2}$, Grammatology ${ }^{3}$ and Des tours de Babel ${ }^{4}$ ) and Glissant (Poétique de la relation) ${ }^{5}$, this article looks at translation from two perspectives: translation as a process that extrapolates the textual dimension, and as a process that can be discussed in terms of textual identity.

We wish to stress the introductory nature of this essay, which is only part of a larger study on the theory of translation and poetry, conducted by the Department of Comparative Literature at the Federal University of Rio Grande do Sul.

Translation - as a process that is based on the search for understanding between different codes, cultures and epochs - can be seen as an act that initiates mediation or, as Heidegger defines it, an "event" that happens in the kernel of the search for identity. Through appropriation (Heidegger) of the textual space of the Other, the intention of undoing, of disconsidering, or even of overcoming alterity becomes apparent. This is not, therefore, a discussion on translatability. We subscribe to the theory that it is possible to translate. The question, then, is not what to translate, or if the translator is gifted or not, or if we can translate Joyce or Guimarães Rosa, or if we need to be faithful to the original text. These questions have already been considered naive by Lambert (1989). What truly counts is our readiness to consider translations in a given historical period, and to view translation as an object of study - hence our interest in who translates, for whom one translates, using which other texts as aids, which register, and which literary, moral, linguistic, political or ideological mode. To these questions we can add the following: to what extent can we translate?

According to Heidegger, equality requires two terms, where one is equal to the other. This is not the principle of identity. In order to be the same, Heidegger says, we only need one term; this one term is identical, the same. The formula " $\mathrm{A}$ is $\mathrm{A}$ " that represents identity says that every " $\mathrm{A}$ " is itself. Within unity, however, there is a vinculum, a synthesis that seems, from the perspective of structuralism, to be the one thing that makes the existence of this unique term possible. To be the Other and itself simultaneously is an idea that, according to Heidegger, gives the western concept of identity the assumption of unity. This unity within the concept of identity constitutes a fundamental aspect of the Being. Wherever we are and however we may relate with a being, we are there, through identity. These ideas, combined with the concept of Zusammengehör, Absprung and 
Ereignis (event of transpropriation), which is associated with Derrida's deconstruction theory, form the basis of our argumentation on the question of translation, which must necessarily take into consideration the two poles of this process: the original text and the translated text, as well as the re-evaluation of the concept of fidelity.

According to Heidegger, Zusammengehör arises from the consideration of a state of being already named, which, nevertheless, remains related to the Being and, in this manner, corresponds to it. In reference to man, Heidegger says that man is this relation of correspondence, and only that. This "only," however, does not mean limitation, but superabundance. Transposed onto our discussion on textual identity we could, perhaps, say that Zusammengehör may exist between text 1 and text 2 , that these texts are maintained in a relationship, and that they correspond to each other.

Still in accordance with these Heideggerian principles, we could transpose his definition (that man is this relation of correspondence, and only that) to texts and translation, and say, not only that the text reflects this (intertextual) relation, and only this, but also that, at the same time, it contains the whole, and is in a relation of correspondence with the whole.

As to the process of translation, though various inferences can be made from these assumptions, one seems to be more relevant to this analysis: the possibility of contemplating the translated text in relation with, if not, identity (in Heidegger's terms) then at least with equality, an idea that is alien to the most traditional theories of translation.

The concept of Absprung seems to be close to the concept of "écriture" (Derrida), although differently codified. Heidegger tries to avoid the representative thought, and conceives the idea of Absprung in an abyss. Absprung, says Heidegger, is a door opened onto the domain where man and Being have forever been and have become each other's property.

On the other hand, Heidegger also stresses the necessity of the unabridged abruptness of the return to the interior of the Zusammengehör. This, he says, is the first step in establishing the mutual relation between man and Being. As far as the theory of translation is concerned, this can also be a fertile epistemological matrix to formalize the concepts of unity and multiplicity of form and meaning, of permanence with respect to the original meaning(s) and of meaning fluctuation of the translated text. Viewed from the perspective of the process of translation and of textual identity, this concept also leads us back to Derrida's concept of "trace" and "writing" (écriture), to which we refer later in this article.

The "Ereignis" also maintains the relations of the theoretical equation that we try to establish between his notions of "Being" and "man," and of writing "text," "original text" and "translated text."

If man shares the nature of "Being," and if "Being" shares the nature of man, the result is a game of appropriation, a peculiar way of giving or of attributing property — an event of transpropriation - in which man and "Being" appropriate each other. The link between Heidegger and Derrida seems to be evident especially if we attempt to demonstrate the fact that ereignet (vb.) and ereignishaft (adj.) can be translated by "happen," "event," "eventual," terms used by Derrida himself in his text Structure, Sign and Play in The Discourse of Human Sciences. As far as translation is concerned, mutual appropriation permits the deconstruction of all logocentric theories that either share the presupposition that meaning originates with the subject/reader, or believe in the stability of meaning, in the purely objective relation between man and reality or even in the hierarchy (centremargin) affecting the theory of translation. As Grigoletto (1992) argues: "one of the consequences of the process of deconstruction of the sign and of writing commanded by Derrida is the need to revise all the theory of reading and of writing." 6 
Heidegger says that the event of transpropriation is the oscillating ambit, before which man and Being reach and appropriate each other's essence when metaphysical determinations are released. To think of the "Ereignis" as an event of transpropriation means to work within the construction of this oscillating ambit itself. Language, for Heidegger, is thus the working tool for this analysis and the most fragile and delicate oscillation. Moreover, in as much as our essence depends on language, we inhabit in the "Ereignis."

The Ereignis, therefore, unites man and Being and the essence of identity becomes part and parcel of the event of transpropriation.

In reference to Heidegger, Gayatri C. Spivak, in Translator's Preface ${ }^{7}$, says that Philosophy has to "restore the memory of the free and controlling meaning in order to find out the original words of languages, by learning to assault the limiting logic of signification." This is what Derrida calls "the other side of the Heideggerian hope (...) the search of the appropriate word and of the unique name."

When commenting on Derrida's ideas, Spivak claims that there is no "nostalgy of lost presence" and that "the Other" of meaning is never contemporaneous: word and thing or thought have never been a unity. The structure of referential words may work not because of the identity between these components of the sign, but because of their relation of difference.

These theoretical presuppositions are easily transferable to the theory of translation, especially if (re)formulated under the assumption that there can only be identity from the evidence or from the manifestation of difference. Translation, says Derrida, is the difference between the signified and the signifier. This difference, however, is never pure or total; translation is even less. This would therefore suggest that the notion of "translation" be substituted by that of "transformation," a regulated transformation from one language into another, from one text into another. Translation is, in this sense, a "version of intertextuality."

In Des tours de Babel ${ }^{9}$, Derrida makes suggestions that can, direct or indirectly, be related to identity. The name Babel, he argues, reminds us of the idea of the inadequacy of one language in relation to another, of language in relation to itself, meaning and the need of figuration, of myth, of deviations and of translation, in an attempt to compensate for that which is negated by multiplicity. Babel is, therefore, the myth of myths, the metaphor of metaphors, the translation of translations. It is, for Derrida, a name that demonstrates incompleteness (the impossibility of saturation). Whether it is used as a proper noun (city) or as a common noun (meaning confusion), Babel evokes various meanings, always delimiting a space where understanding is no longer possible, be it a space formed by a proper noun, or the total absence of such a noun. Punishment is imposed because man has attempted to give himself a name and tried to appropriate totality. In building a tower or a city, naming it in a universal language, Man was condemned to dissemination; a condition that imposes and, simultaneously, prohibits translation.

Babel is the origin of multiplicity itself. It is in a translated text that we read this narrative today. The name Babel is the transparency that Babel (= confusion) has not destroyed: the multiplicity of languages and the meaning of translation.

According to Derrida, God submits the Semites to translation. Thus, as something necessary and impossible, translation becomes law; as Derrida affirms, "nothing is more serious than a translation." The original text is indebted to the translator, in that it needs to be translated and clamours for translation. Developments in translation theory have been marked by the passage from logocentrism to deconstruction, and has moved translation from the periphery to the centre of debate on language and the human condition as such. 
Contemporary philosophy holds a certain fascination for translation. We have come to the point where the text is perceived as live and being kept alive through reading and translation. Indeed, to reject translation is to reject life itself.

Translation and translatability is what guarantees continuity, the afterlife, the dissemination of meaning, and it is what characterizes men as "beings, inventors of metaphors."10

The transformation of a text from one language or culture to another will always be impossible if we understand it as a transportation of meaning, but it will always be possible if we accept both the idea of translation as transformation, and the impossibility of returning to the "same" (either the same book, or the same text).

In a world made up of differences, the return to the same (the original) is not possible for the simple reason that there is no such thing as an original, or a "same" immutable form to which we can return. 11

As far as identity is concerned, the basic difference between Heidegger's and Derrida's postulates is that Heidegger provides us with ways of thinking about the principle of identity, through certain concepts already examined above, as well as with elements that allow us to conclude that identity, as he defines it, can not be established by the process of translation; translation works on the difference between two codes. Since identity, for Heidegger, comes from the same to the same, we can infer that, within his epistemology, translation can only happen on the level of equality. Derrida, on the other hand, taking structuralism to its limit, displaces the referential of the difference against which identity is established beyond the sign, and conceives of alterity as an ever absent trace, as a mark of absence, an idea that is the condition proper to thinking and experience. The idea that language is simultaneously used and erased strikes us as contradictory and unacceptable within the logic of identity. This necessarily presupposes a change in our way of thinking: if the authority of the text is occasional and the sign a fleeting moment, each reading inscribes a new "writing" extracted from the polysemy of multiple meanings, out of which one is selected and established as meaning. 12 From these considerations, we can infer the provisional nature of each translation and the necessity of constant re-translations. In this manner, the highly valued original text can remain meaningful and the identification desired by the reader may be conceived within a polysemic universe. In other words, common traces can establish the structure of reading, of comprehension, in such a way that translation and the translator can bring about the accomplishment of their tasks, as Benjamin suggests in "The Task of The Translator." Translation is no more responsible for the total or partial death of texts: it "becomes paradigmatic of all linguistic interchanges and, what is the same, of all human interchanges, associated to life and 'to resistance to death"."13

Translation, then, is no longer marginal. It becomes law, a productive form dictated by the original text, and without which it "does not disseminate or reproduces" (Derrida).

Arroyo, in Tradução, says:

The recognition of this power, ignored during such a long time opens exciting perspectives for research, that can finally get rid of its old complex of inferiority and of its compulsion to apologize and, consequently, leave apart the indefectible comparisons between the 'grandeur' of the original and the infidelities committed by translation. In renouncing to its patchmending condition, translation also loses its innocence, as, for example, in the motivations that underlie the nature of intervention that it makes in the texts it chooses to transform and to disseminate. Translation assumes itself as an inevitable form of conquest an of power that necessarily re-writes the past and appropriates other cultures and other languages. ${ }^{14}$ 
Heidegger and Derrida can, therefore, be considered in the same light when translation is understood as transformation and as appropriation. If power and identity seem inherent and essential to the psychological balance of man, it would be better, then, if they could occur in the ambit of language and of translation where the process of appropriation undergoes the transformation and assimilation of differences in such a way that identities can be constructed in a gradual, democratic and peaceful process.

This, however, does not seem possible as long as purely logocentric theories predominate; the changes in the historical process are also very painful for a mentality that conceives of and understands the "being in the world" from the perspective of submission.

The practice of translation and the awareness of the importance and the need to translate can certainly act as a catalyst for the dissolution of the conceptual rigidity and the establishment of more subtle forms of identification between men through their languages. This might, perhaps, be the first step of another long journey toward the possibility of translating from the level of identity, in the sense proposed by Heidegger.

For the time being, however, Derrida's ideas seem to be more suitable, for he asserts that the translator does not translate: there is no solution for the translator, there is only the possibility of opposition, comment, paraphrase or exploration.

As the experience of multiplicity of languages, Babel continues to be untranslatable, while it reveals the experience of translation itself. "Translation proper" (both interlinguistic and post-babelic) does not happen. But, according to Derrida, there may be translation as such, as well as translation in a figurative sense:

In order to translate the one into the other, within the same tongue or from one tongue to another, in the figurative or in the proper sense, one would engage upon a course that would reveal how this reassuring tripartition can be problematic. Very briefly: at the very moment when pronouncing "Babel" we sense the impossibility of deciding whether this name belongs, properly and simply, to one tongue. ${ }^{15}$

On the other hand, in his name, God breaks up the rational transparency and interrupts the colonial violence of linguistic imperialism. Man's destiny as a translator is then determined. Not only does the constructor of the tower lay claim to translation, in the hope of linguistic unicity, but so does the deconstructor: God himself remains in a relation of dependency and complementarity, and the translator must accomplish his task of mediation. This task of mediation, in other words, can be understood as the possibility of the "event" proper, that is, the event that brings about the process of identification, understanding and signification of not only the sacred but also the human, the "proper" and the "common," the "original" and the "translated," out of the limiting hierarchy of logocentrism.

Derrida suggests that no theory can annul the confusion of Babel. We are, he says, condemned to it. All we can do is understand it from its own premisses. Derrida's main contribution to the theory of translation seems to be his emphasis on the idea that it is necessary not to try to explain Babel from its origins, since these are deconstructive in and of themselves.

The present state of theoretical development, therefore, seems to suggest the notion that translation may be perceived as a process and not as a final product, and the idea that the attempt to establish textual identity as perfect equivalence based on a matrix model is far from taking this process into account, since its premisses are unstable: it has become a theoretical sophism.

In relation to the question of identity, Heidegger seems to have been extremely lucid. Derrida, falls back on Heidegger's idea of Absprung and the abyss. Considered 
exclusively from the notion of writing, however, Derrida can only lead us to the evidence that we are in the aporia, in the "mise-en-abîme" which is, paradoxically, our only way of escaping from the captivity imposed by the stable meaning which appears as controlling, imperialist and insufficient. The text can only be explained, read and translated by another text: this is the instrument of comprehension given to us.

Gregory Rabassa, in No Two Snowflakes are Alike: Translation and Metaphor, 16 gives further consideration to these thoughts about translation. He says that translation can never be identical to the original and that the word is no more than a metaphor of an object or of another word. Moreover, he claims that, notwithstanding similarities, there can be no equal metaphors. Words, he says, do not simply describe the object, but denote the spirit involved in it as well; translation, therefore, has to extrapolate the textual dimension and consider the identities in the ambit of the feelings which underlie the textual surface. Regarding the questions of identity and translation, the author compares the act of naming in the Genesis with the similar situation of XVth-century discoverers, who had to name a flora and fauna that were completely strange to their experiences. He reminds us that, in the eagerness of appropriation, Europeans had three options: first, to accept the native name; second, to give a name similar to an existing European name; and third, to create a new name. From then on, it seems that our own identity began to take form: since our existence is founded in language, translating can also mean a return to this founding mode of identification, as a possibility of establishing identity. As we saw above, we may never be able to achieve the total reconstitution of the meaning or to establish identities (A is $\mathrm{A}$ ) in translation. The dated translation, however, may become useful for the analysis of texts translated at a certain time, according to historical objectives, and for understanding periods when certain signifiers referred to different signifieds from today's. For each new historical period, and for each different cultural milieu, re-translation is a must.

As "producers of metaphors," whose existence and identification depend on the language, we participate in the translation process from the very moment we pronounce our first word. If Babel condemns us to translation, Sisiphus impels us to re-translation.

In order to dispose of the "negative connotations" 17 usually attached to the states of translation we need to re-think translation on the basis of its own premisses as an inherent and constituent factor of the subject, as well as a constant process of formulation and reformulation of the same, where Babel is no longer viewed simply as a punishment imposed by an external authority, but as the human condition of incapacity to achieve totality.

Translation doesn't occur from one determined original state (pre-babelian?), but from the human condition itself. Hablar es hablar en lenguas and aprender a hablar, es aprender a traducir says O. Paz. ${ }^{18}$ Formal identity between speech and translation seems evident in his argumentation. If translation is a process that occurs within languages and if it is, by itself, an instrument consisting of absence and difference, the criteria of perfection, fidelity and perfect identity between the texts, which have been the norm in translation theory, strike us as inconceivable or, at the very least, incoherent.

Antoine Berman's text ${ }^{19}$ on platonism and translation is a successful attempt at equating philosophical and traditional theoretical principles with Derrida's deconstrution. The author lays stress on the close ties between translation and philosophy. He argues that the possibility of dissociating the meaning and the letter grants translation the status of process, which establishes the rupture between the divine and human languages. The theory of translation has always been defined from a platonic perspective (the logos). It is neither the practice, nor the theories that are platonic, says Berman, but translation itself. Regarding the letter and the meaning, it is the meaning that does not change, but which 
contains more "Being," and which moves from one language to another as an invariable ideality.

Translation, then, is not founded on this rupture. It is the act that accomplishes the rupture. The pure reformulation, says Berman, is not enough to make jaillir le sens: heterogeneity is necessary.

Commenting on Derrida's ideas, Berman says that philosophy searches for a more transparent and universal logos and that by "dropping corporality" translation elevates itself above the senses, with a movement of verticality towards an ideal language. Moreover, it also distinguishes the material beauty of the original from the formal beauty of the translation, where "the pure articulation of ideas is manifested brilliantly and harmoniously." In addition to Novalis' idea that translation is the act that allows the spirit to manifest itself, Berman's comments lead us back to the question of identity and to the conclusion that identity can only happen in an extratextual dimension, "dans une forme étrangere et aérienne" (Novalis) ${ }^{20}$ in the "écriture" or in any other place but the translated text. The translated text is seen as a "space of transformation and not of research of hypothetical equivalences" (Berman). For Berman, translation simultaneously liberates the meaning and destroys the work (text). The translated text always refers to another text and, consequently, is not awarded the status of "work" even though it may reveal the truth or have a better form than the original.

Berman's comparison of the translated text with the moon, which shines with a borrowed, pale light, allows us to make two inferences: first, valuing, and second, devaluing translation, for in the same way that it only reflects the light of another star, it also acts as a mirror that reflects and intensifies this same light.

It is in the field of Philosophy that the relevance of translation in the western epistemological context has been rethought and given higher status. Philosophers are the ones who best perceived the "logos," the "meaning," the "present of the spirit" in the translation process. These are but some of the reasons for renewed interest in translation studies.

The idea that the original lives in the translation (Benjamin) ${ }^{21}$ seems to have been the main cause of this renewal. What has to be kept in mind, however, is the notion that these studies will not get very far if the criteria and the concepts related to the linguistic, the poetic and philosophic nature of the sign are not reconsidered in a new scholary light, whose basic premiss is that there is no possibility of a purely objective relation between man and reality, between signifier and signified, between the original and the translated form. "Translation deconstructs the logocentric notion" 22 that the text is a category independent of the reader, argues Arroyo. This, however, doesn't annihilate the human, the context, the historical, the local or the relative. What it does, in fact, is focus on the relations between the written text and the re-written (re-inscribed) one, considering them, as Spivak says, not as relations of "patency and latency but rather as the relation between two palimpsests." 23

In the same manner, Biguenet ${ }^{24}$ reminds us that reading is translation for the second time, and that it holds the secret of human understanding and of social communication in its essence. Reading re-establishes the uncertainty of the word, produces meaning and generates uncertainty. Translation, then, will always be a process. The word simply starts this process that, in turn, seeks to demonstrate the "how" and not the "what" in the act of reading. It also demonstrate that the translator's effort will always be directed towards the relations between the word and its etymology, between the word and its cultural environment, between the word and its historical context in a particular text.

As a process, translation can not, therefore, be considered as a reductive activity, for what the translator finds out is not the equality of meanings, but the differences, already purged and purified. If seen under the perspective of identity, of difference, of 
relation and of mediation, which has been the starting proposition of this paper, the explanation of these differences is one of the most essential contributions of the translator as a mediator that acts out in the inter-space between the evidence of the textual surface and its semiotic, etymological and cultural components.

In conclusion, we refer to the notions of errantry, exile, and rhizomes that Glissant presents in his chapter L'errance, l'exil. If we transport (trans-late?) these into the context of our discussion, we could perhaps adjust our focus and consider the errantry and the exile of meaning itself, related to language and to translation. Translation, then, can be seen as a process that starts in the search for identity, that, as Glissant says, delves into the opacities of the world (word), and that renounces its claim to totality. Translation, therefore, reinforces identity in the search of something unattainable, and therein resides its greatest value.

In negating the pole (metropoles, models, original text) this exile is the search for the Other - the one thing that recognizes the differences and that thinks through and from them. The most productive effect of this is the possibility of shared knowledge, without strangeness, a sort of identity that presupposes the relation with the Other, and takes it for granted.

What Heidegger may not have seen is that the difference is, perhaps, no more than the external manifestations of the same rhizome that feeds them and provides them with a common sap and vigour. When this rhizome is continuous, uninterrupted, we might, perhaps, admit the possibility of identity (even in Heidegger's terms), synthesis, or at least of catching a glimpse of, the shadow of the "écriture" in the process of translation.

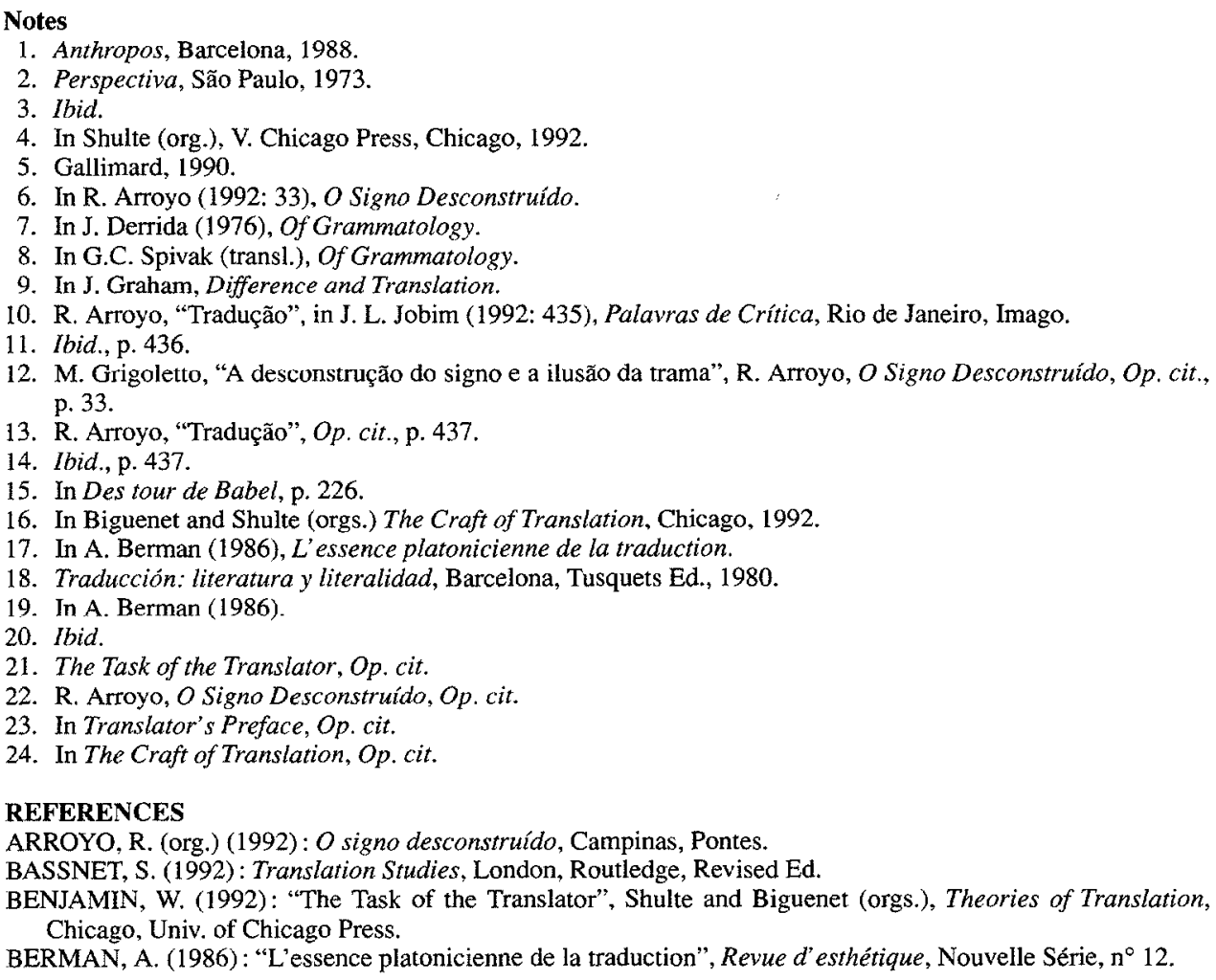


BERMAN, A. (1985): Les tours de Babel essais sur la traduction, Trans-Europ. Rep.

BIGUENET and SHULTE (1992): The Craft of Translation, Chicago, Univ. of Chicago Press.

BIGUENET and SHULTE (1992): Theories of Translation, Chicago, Univ. of Chicago Press.

DERRIDA, J. (1976): Of Grammatology, translated by G. C. Spivak, Baltimore, John Hopkins V.P.

GLISSANT, E. (1990): Poétique de la relation, Paris, Gallimard.

HEIDEGGER, M. (1985): Identidad y diferencia, Barcelona, Anthropos.

JOBIM, J. L. (org.) (1992): Palavras de críicica, Rio de Janeiro, Biblioteca Pierre Menard Omago.

LAMBERT, José (1989): "La traduction", Angenot, M. et al., Théorie littéraire problèmes et perspectives,

Paris, Presses Univ. de France.

PAZ, Otávio (1980): Traducción, literatura y literalidad, Barcelona, Tusquets Ed.

STEINER, G. (1975): After Babel Aspects of Language and Translation, Oxford.

TOURY, Gideon (1980): "The Nature and Role of Norms in Literary Translation", In Search of a Theory of

Translation, Tel Aviv. 